\title{
Genetic influences of autism candidate genes on circuit wiring and olfactory decoding
}

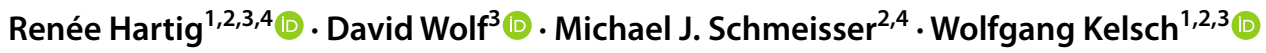

Received: 18 September 2020 / Accepted: 10 December 2020 / Published online: 30 January 2021

(c) The Author(s) 2021

\begin{abstract}
Olfaction supports a multitude of behaviors vital for social communication and interactions between conspecifics. Intact sensory processing is contingent upon proper circuit wiring. Disturbances in genetic factors controlling circuit assembly and synaptic wiring can lead to neurodevelopmental disorders, such as autism spectrum disorder (ASD), where impaired social interactions and communication are core symptoms. The variability in behavioral phenotype expression is also contingent upon the role environmental factors play in defining genetic expression. Considering the prevailing clinical diagnosis of ASD, research on therapeutic targets for autism is essential. Behavioral impairments may be identified along a range of increasingly complex social tasks. Hence, the assessment of social behavior and communication is progressing towards more ethologically relevant tasks. Garnering a more accurate understanding of social processing deficits in the sensory domain may greatly contribute to the development of therapeutic targets. With that framework, studies have found a viable link between social behaviors, circuit wiring, and altered neuronal coding related to the processing of salient social stimuli. Here, the relationship between social odor processing in rodents and humans is examined in the context of health and ASD, with special consideration for how genetic expression and neuronal connectivity may regulate behavioral phenotypes.
\end{abstract}

Keywords Behavior $\cdot$ Mice $\cdot$ Olfaction $\cdot$ Social $\cdot$ Shank2 $\cdot$ Synaptic wiring

$\begin{array}{ll}\text { Abbreviations } \\ \text { AOS } & \text { Accessory olfactory system } \\ \text { AON } & \text { Anterior olfactory nucleus } \\ \text { ASD } & \text { Autism spectrum disorder } \\ \text { E/I } & \text { Excitation to inhibition balance } \\ \text { MC } & \text { Mitral cell }\end{array}$

Renée Hartig and David Wolf are the first authors and contributed equally.

Wolfgang Kelsch

wolfgang.kelsch@zi-mannheim.de; wokelsch@uni-mainz.de

1 Department of Psychiatry \& Psychotherapy, University Medical Center, Johannes Gutenberg-University, 55131 Mainz, Germany

2 Focus Program Translational Neurosciences (FTN), University Medical Center, Johannes Gutenberg-University, 55131 Mainz, Germany

3 Central Institute of Mental Health, Medical Faculty Mannheim, Heidelberg University, 68159 Mannheim, Germany

4 Institute for Microscopic Anatomy and Neurobiology, University Medical Center, Johannes Gutenberg-University, 55131 Mainz, Germany
MOS Main olfactory system

MTC Middle tufted cell

OSN Olfactory sensory neuron

PCX Piriform cortex

\section{Introduction}

Olfaction is important for many species, with a strongly conserved evolutionary basis (Heymann 2006; Auer et al. 2020) and far-reaching effects on the ongoing neuronal processes related to a range of vital functions expressed by chemosensory beings. The decoding of olfactory information is ever more essential to understanding its influence on behavior, in guiding social interactions, and in learning and memory. Invaluable insight has been drawn from the use of murine and invertebrate models, for instance, to study the underlying molecular and cellular processes, often using methodological techniques not feasible in humans. Transgenic animals that model human disorders have great potential in vital scientific research and in developing applicable treatments.

One disorder that bears prevalence in humans is autism spectrum disorder (ASD), whereby a range of behavioral deficits in the realm of social interaction and communication 
is evident (Muhle et al. 2018). This neurodevelopmental disorder manifests early in childhood and is often accompanied by repetitive and/or stereotypical behaviors (American Psychiatric Association 2013). In the USA, an estimated 1-in-54 children and adolescents were diagnosed with ASD between 2014 and 2016 (Xu et al. 2018). The numbers are particularly striking as the calculated prevalence at the turn of the twenty-first century was approximately 1-in-150 (Autism and Developmental Disabilities Monitoring Network Surveillance Year 2002 Principal Investigators), indicating a gradual increase over time. While the proportion of ASD diagnoses may plateau, as potentially indicated by a rather steady percentage between the 2014 and 2016 period, it is unknown if clinical expertise and diagnostics have truly reached a threshold for stemming the decades-long increase in ASD cases.

Given that a plethora of genetic and environmental risk factors have been identified, pointing to a complex, polygenic etiology of ASD (Sung et al. 2005; Jansen et al. 2020), it is to no surprise that the causes of ASD are not fully understood. The extent to which mutated genetic expression is influenced by environmental factors and the effects on neuronal assemblies is discussed here. Furthermore, the role of olfactory decoding is examined, especially within the context of social information processing, and its effects in ASD, largely considering the genetic links to synapse formation and neuronal wiring.

In particular, the impaired social behavior and communication in patients with ASD is not an isolated higher-order dysfunction, but rather a broad dysfunction of many brain circuits entailing both impaired primary sensory processing and perception (Robertson and Baron-Cohen 2017). Sensory deficits in ASD patients have been reported to occur early in development (Kern et al. 2006) and appear to predict clinical outcomes later in life (Kaldy et al. 2011; Gliga et al. 2015). It is, therefore, promising to study the sensory processing of social information in healthy individuals, patients, and in ASD models at various levels, whereby the underlying genetic basis and convergence of behavioral and physiological phenotypes can be identified.

The importance of olfaction for social cognition and its impairment in ASD is highlighted in this article, largely drawing from insight gathered using murine models and from clinical cases. The genetic determination of olfactory circuits and the influence of ASD candidate genes on social odor processing and olfactory decoding is also discussed. Notably, this is not a comprehensive review covering all the literature on the topics, but rather a focused depiction of the relationships as illustrated by exemplary studies, noting the current progress in the field, and where future studies may progress our understanding of social olfaction within the context of supporting healthy function and behavior.

\section{Olfaction in social cognition and ASD}

Olfactory stimuli influence a myriad of social behaviors. This is, in part, because olfactory stimuli produced by conspecifics carry information relevant for behavior and social cognition. Olfaction-dependent social behaviors include mating, aggression, and social recognition (Liberles 2014; see also Fig. 1). Such considerations of ethology may provide additional opportunities to study functional impairments along a range of social tasks.

Traditionally, many different behavioral assays have been designed and validated for specific domains of social behavior. To name only a few which are widely used for the characterization of social behaviors, there is the 3 -chamber social interaction test for sociability (Fig. 1c, left; Fig. 1d), social transmission of food preference (Fig. 1b), and the partner preference test, or social novelty preference (Fig. 1c, right), for social recognition and memory. While behavior demonstrated by social task performance is greatly influenced by olfaction, it should also be acknowledged that sensory input from other modalities, such as vision and audition, can also play a role in modulating behavior. By design these tests examine a limited subset of naturally occurring social behaviors, and the exact role of olfactory processing remains unknown and critical care should be taken to control for the influence of other modalities of sensory input.

Rodents actively explore their environment in an effort to sample information and process relevant social cues. Social odors are mixtures of volatile and non-volatile molecules produced by a conspecific and signal individuality or elicit a certain behavioral response. Primary sources for these are exocrine glands in the facial area, sweat, urine, and feces. Nevertheless, odors can carry social information even if they are not directly emitted or produced by an interaction partner but are associated with a social value (e.g., the perfume of your partner). With this, odor association and sampling context can further influence action and modulate behavior.

While much attention has been paid to perceptual sensory deficits in tactile sensitivity, auditory filtering, and in the visual domain (e.g., misinterpretation of facial expressions or body language) (Thye et al. 2018), there is increasing evidence that chemo-senses, such as taste and smell, are impaired in ASD (Bennetto et al. 2007; Boudjarane et al. 2017; Barros and Soares 2020). Children with ASD are often described as "picky eaters" by their parents and studies show, indeed, that food selectivity is narrower than in typically developing children (Williams et al. 2005; Schreck and Williams 2006; Cermak et al. 2010). This phenomenon is often attributed to greater sensory sensitivity to food texture, but smell plays a crucial role (Cermak et al. 2010). 

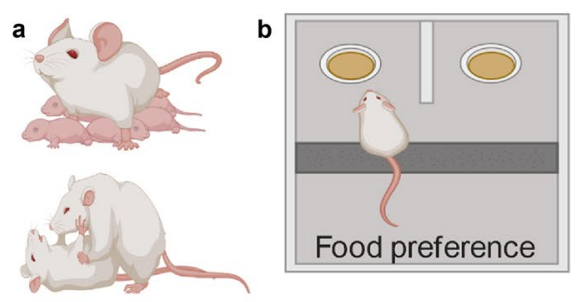

d

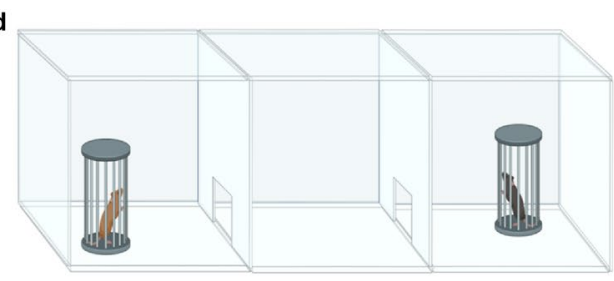

Fig. 1 Social behavior assessment in murine models. Social interactions can be studied using behavioral assays, where the behaviors observed in different settings help inform the role of social cues. Such assays aid in isolating specific sensory components from an interaction experience. Social behaviors include interactions with a offspring, facilitating maternal behavior (top), such as pup retrieval, and from conspecifics which can elicit aggressive behaviors (bottom). The b food preference test and c sociability (left) and social novelty pref-

Several studies have investigated and characterized olfactory function in ASD patients, but reveal partially divergent results in terms of how sensitivity to odor identification and enhanced perception is compared with typically-developed individuals (Bennetto et al. 2007; Galle et al. 2013; Addo et al. 2017; Muratori et al. 2017). Two meta-analyses that looked at odor detection thresholds found large heterogeneity in effect sizes and offered no clear conclusion whether there is hyper- or hypo-sensitivity in the olfactory system across the spectrum of ASD patients (Tonacci et al. 2017; Larsson et al. 2017). One of these meta-analyses, however, found more consistent results for impaired odor identification (Tonacci et al. 2017). All in all, any divergence across these studies might relate to the different etiological roots of autism in individual cases across the studied population. Further studies are needed to more reliably determine the olfactory impairments in ASD (Larsson et al. 2017). Also, many studies rely on active odor reporting from participants, which could be unreliable in cases with impairment of communication, or with young patients.

A more promising read-out for olfactory processing is the sniff response to odors, especially in clinical populations with impaired communication and with subliminal odor presentation. Sniff pattern and its modulatory change are more than just the subject's breathing rhythm. Salient odors evoking emotional responses have been found to modulate olfactory cortices as well as breathing

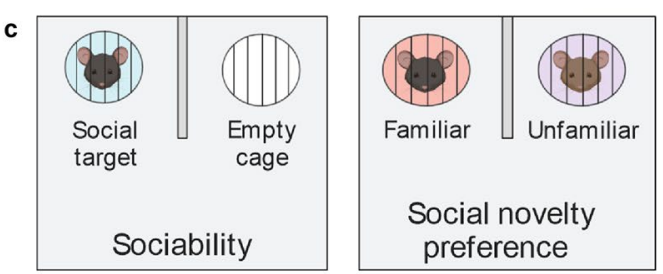

e

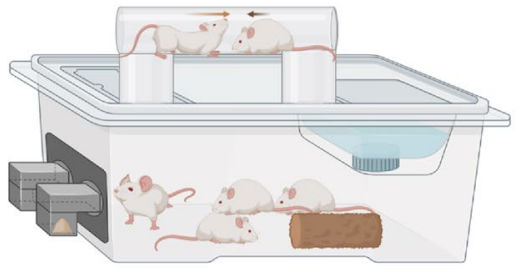

erence (right) tests can also be implemented in a d 3-chamber testing arena where social cues can be positioned at each end of a linearly oriented row of chambers, consisting for instance, of a neutral middle zone where test animals make a decision where to spend most time exerting exploratory behavior. e A housing environment where odor and water ports have been integrated to run conditioning paradigms and examine group behavior (e.g., social hierarchies). Figure utilized BioRender for standard graphical illustrations

rhythmicity (Krusemark et al. 2013). Notably, breathing and olfaction are highly coupled functional processes (Perl et al. 2019). In a study that non-invasively monitored sniffing in socially interacting rats, sniff behavior conveyed information about the hierarchy and social status between two interaction partners (Wesson 2013).

Humans actively (often subconsciously) sample chemosensory cues from the social domain. For example, after shaking hands with a stranger from the same sex humans sniff their hand significantly more, but after shaking hands with someone from the opposite sex, only significantly sniff the hand that did not touch the stranger (Frumin et al. 2015). Taking advantage of these features of the sniff response, a study investigated the response to pleasant and unpleasant odors in typically-developing and autistic children (Rozenkrantz et al. 2015), finding that healthy children had a stronger decrease in normalized sniff volume after presentation of an unpleasant odor as compared with a pleasant odor. Children with ASD, however, showed no significant dissociation of sniff response to the two odors, and the severity of autistic symptoms was correlated to aberrant sniffing (Rozenkrantz et al. 2015). Since perceptual impairments in ASD in visual and other sensory domains are influenced by social cues, it is of great interest how the processing of social chemosensory signals is impaired in patients.

In regard to hand sniffing after greeting a person, autistic adults exhibited social odor sampling behavior equal to healthy controls (Endevelt-Shapira et al. 2018). Autistic 
males were also equally capable of discriminating body odors (i.e., sweat collected from skydivers or men walking) and rated them comparably to healthy controls in pleasantness, intensity, and fearfulness. However, when presented with either "fear sweat" from the skydiver or control sweat (both below perceptual threshold), healthy adults exhibited greater autonomic arousal (by electrodermal activity) to fear sweat than to control sweat, while ASD patients showed no change in the autonomic response (Endevelt-Shapira et al. 2018). The opposing behavioral response between ASD participants and healthy participants to social chemosensory cues also reoccurred in an implicit measure of trust and could be induced by synthetic odors (Endevelt-Shapira et al. 2018). This hints to a disrupted processing of olfactory stimuli, especially of social odor cues in ASD, whereby the subliminal effects of effects of social stimuli on autonomic circuitry and function are abnormally processed. Hence, a component of the stimulus origin and setting plays a crucial role in impairment selectivity for social as opposed to nonsocial odor processing.

\section{Autism candidate genes in olfactory circuit wiring}

Throughout life, the olfactory system is a highly malleable and plastic network due to the continuing integration of adult-born neurons and activity-dependent synaptic plasticity. However, olfactory circuit assembly during prenatal and early development is innately determined by genetic factors and regulated by a variety of transcription factors. Genetic factors dynamically influence not only circuit assembly but also synaptic connectivity. Transcriptional control of the main olfactory bulb (MOB) circuit assembly and its topographic organization, for one, has been reviewed previously (Sakano 2020). However, here the focus is on the transcriptional control of cortico-bulbar connectivity due to its potentially greater implication in ASD, although much less is known about this part of olfactory circuit development.

As a spectrum disorder, varying phenotypes may be expressed across individual ASD cases as subject to the underlying genetic mutation, and the same phenotypes can be expressed by different genetic mutations. Environmental factors, such as upbringing, additionally influence the development of autistic phenotypes and affect sensory information processing and valuation. Undoubtedly, the causes of ASD are multi-faceted and should be considered from a holistic perspective which bridges genetics and behavior.

The rodent olfactory system processes volatile and nonvolatile stimuli with both playing a role in social odor processing. Non-volatile components, such as steroid derivatives in urine, are primarily processed by the accessory olfactory system (AOS) (Baum and Kelliher 2009; Liberles 2014). The primary sensory neurons of the AOS are located in the vomeronasal organ (VNO) at the base of the nasal septum. They detect stimuli by a class of G-protein coupled receptors, which differ from olfactory sensory neurons (OSNs) in the olfactory epithelium. VNO sensory neurons extend their axons to the glomeruli of the accessory olfactory bulb (AOB), which is an adjacent, but separate structure to the MOB. AOB outputs predominantly bypass the olfactory cortex and project directly to the medial nucleus of the amygdala (MeA) and the posterior bed nucleus of the stria terminalis (BNSTp) (Holy 2018).

Volatile components of odors are mostly sampled and processed by the main olfactory system (MOS). The neural circuit of the MOS starts with the OSNs in the olfactory epithelium projecting to the glomeruli of the MOB, essentially forming a topographic map (Mombaerts et al. 1996; Mombaerts 2006; Imai and Sakano 2007; Takeuchi et al. 2010; Wu et al. 2018). Mitral cells and middle tufted cells (MC/MTC) in the MOB then project to primary olfactory regions, such as the piriform cortex and the anterior olfactory nucleus, as well as to the olfactory tubercle of the ventral striatum and other limbic regions. Within the MOB, MC/ MTCs extend lateral dendrites, forming dendro-dendritic synapses with inhibitory granule cells, to elicit lateral inhibition of other MC/MTCs involved in local oscillatory activity and odor discrimination (Margrie et al. 2001; Lepousez et al. 2014; Kollo et al. 2014). Inhibitory granule cells are located at the center of the MOB and form the largest cell population. The abundant top-down influence from olfactory cortices to the MOB mainly targets the granule cells (for a review of the MOS, see Brann and Datta 2020; Schäfer et al. this issue). Top-down influence on MOB by the AON and the anterior piriform cortex has been described previously (Boyd et al. 2012, 2015; Markopoulos et al. 2012; Rothermel and Wachowiak 2014; Oettl et al. 2016; Quintela et al. 2020 and reviewed by Rothermel et al. this issue).

Various genetic factors dynamically influence the assembly and refinement of cortico-bulbar synaptic connectivity. However, little is known about their functional implications in coding (Ravi et al. 2017). Future studies warrant investigation of the influences of olfactory coding genes on neuronal population activity and behavioral output.

To further understand the physiological signatures of disease-related phenotypes, the underlying neuronal circuitry can be examined. Previous research on ASD, largely focused on microcircuitry dysfunction (Rinaldi et al. 2008), suggested that ASD-related perturbations of neuronal circuit wiring disrupt the balance of excitatory and inhibitory activity (E/I balance). This imbalance has been implicated in a variety of other neuropsychiatric disorders and diseases, for instance, in stress disorders (Rosenkranz et al. 2010; McKlveen et al. 2019), schizophrenia, and epilepsy (Marín 2012; Selten et al. 2018).

Genetic deficits in neuropsychiatric and neurodevelopmental disorders with disturbed $\mathrm{E} / \mathrm{I}$ balance and synaptic 
weighting (Selten et al. 2018) also influence sensory processing and brain function at the systems-level. Several ASD candidate genes have been identified throughout the last two decades. A significant number of these genes encode proteins involved in the formation and maintenance of synaptic contacts, including Cntnap2, Nlgn3, Shank2, Shank3, and Tbr1 (see also Table 1), to name some of the most relevant (Huang et al. 2014; Bourgeron 2015; De Rubeis and Buxbaum 2015; de la Torre-Ubieta et al. 2016). The functional consequences of altered synaptic development and the function of autism candidate genes are highlighted here using an example of selected Shank-family members.

Numerous studies have suggested that Shank impairment is involved in the development of ASD (Grabrucker et al. 2011; Jiang and Ehlers 2013; Guilmatre et al. 2014; Monteiro and Feng 2017). Shank proteins comprising Shank1, Shank2, and Shank3 are associated with postsynaptic scaffolding and play a critical role in structuring excitatory synapses (Schmeisser 2015; Ey et al. 2020). Under-connectivity, as defined by the reduced growth of dendrites, axons, and synapses (Fernandez et al. 2019), may be reflected at the systems-level, and characterized by reduced, or aberrant, inter-regional connectivity. Such pathogenic features have been illustrated, for instance, by Shank3 deficiency; whereby, functional connectivity was affected as well as the structure of prefrontal regions (Pagani et al. 2019). At the molecular level, Schmeisser and colleagues (2012) found that both Shank2 and Shank3 mutant mice displayed altered synaptic expression of receptors specific to excitatory synaptic transmission in various brain regions. Furthermore, depending on the localization of Shank2associated neuronal deficits, different ASD phenotypes can be observed (Kim et al. 2018). For instance, Shank2 deletion in parvalbumin-positive neurons leads to moderate hyperactivity and enhanced self-grooming (Lee et al. 2018), while Shank2 deficiency in cerebellar Purkinje cells has been linked to impaired social interactions as well as motor coordination deficits (Peter et al. 2016). Importantly, data also indicate that Shank2 deficiency in the hippocampus and striatum contribute critically to the phenotypic impairments in social and motor behaviors (Schmeisser et al. 2012; Won et al. 2012). Overall, in mouse models of ASD, sensory, prefrontal, hippocampal, cerebellar, and striatal regions, as well as the circuits that connect them are perturbed (Golden et al. 2018). These circuits differentially contribute to ASD-related behaviors, a pattern that has emerged across several major ASD mutant mouse lines (Rothwell et al. 2014; Bey et al. 2018; Zerbi et al. 2018; Guo et al. 2019).

\section{Olfactory coding of social cues}

Thus far, the importance of olfaction in guiding social behavior not only in rodents but also in humans was illustrated. We further described the influence of genetics on neuronal assemblies and synaptic wiring in the olfactory system. Next, is to address the question of how social odor information is typically processed. The circuitry supporting social odor processing occupies several brain regions, and these sub-regions form distinct, parallel functional pathways, as evidenced by human fMRI (Zhou et al. 2019).

Intact social behavior is reliant upon both the MOS and the AOS. Investigating immediate early gene ( $c$-Fos) expression in the male brain after interaction with a sameor other-sex conspecific, or with a non-social odor, showed a large overlap in the activation of MOS-associated regions, namely, the $\mathrm{AON}$, piriform cortex, cortical amygdala (CoA), and the lateral entorhinal cortex (Kim et al. 2015). AOS-associated brain regions like the MeA and parts of the CoA showed higher $c$-Fos expression for opposite sex stimuli. Of note, male interaction with female conspecifics showed specific activation of the tenia tecta and post-piriform transition area and stronger recruitment of the MOS-pathway-associated ventral striatum and orbitofrontal cortex (Kim et al. 2015).

In a functional magnetic resonance imaging (fMRI) study, both the MOS and AOS pathways were activated after the presentation of volatile urine odors and pheromones with different selectivity (Xu et al. 2005). After lesioning of the main olfactory epithelium, mice lost the ability to distinguish between volatile and non-volatile opposite-sex olfactory cues (Keller et al. 2006). In contrast, the destruction of the VNO resulted in no impairment of sex discrimination and recognition of volatile and non-volatile odor components (Pankevich et al. 2004). Mutant studies with impaired action potential generation in the VNO sensory neurons showed reduced aggressive behavior and increased mounting behavior towards a male intruder (Clancy et al. 1984; Leypold et al. 2002). This further implicates the AOS in aggression and sexual behavior, but not for individual recognition (Chamero et al. 2007, 2011).

Most social behavior, typically associated with the MOS, needs to be flexible and context-dependent. Two chemically identical social odors can elicit different behavioral responses based on the internal state of the animal. This internal state can contain learned associations and values of an odor, as well as physiological latent variables like arousal, attention, and environmental context (Chen and Hong 2018). For example, after associative learning, mice showed preference to a previously neutral odor after conditioning the odor with a social cue (Choe et al. 2015).

Moreover, an example of social transmission, as seen with food preference, is where mice favor one source of food over another if they have smelled it on the breath of a demonstrator animal before (Munger et al. 2010; 


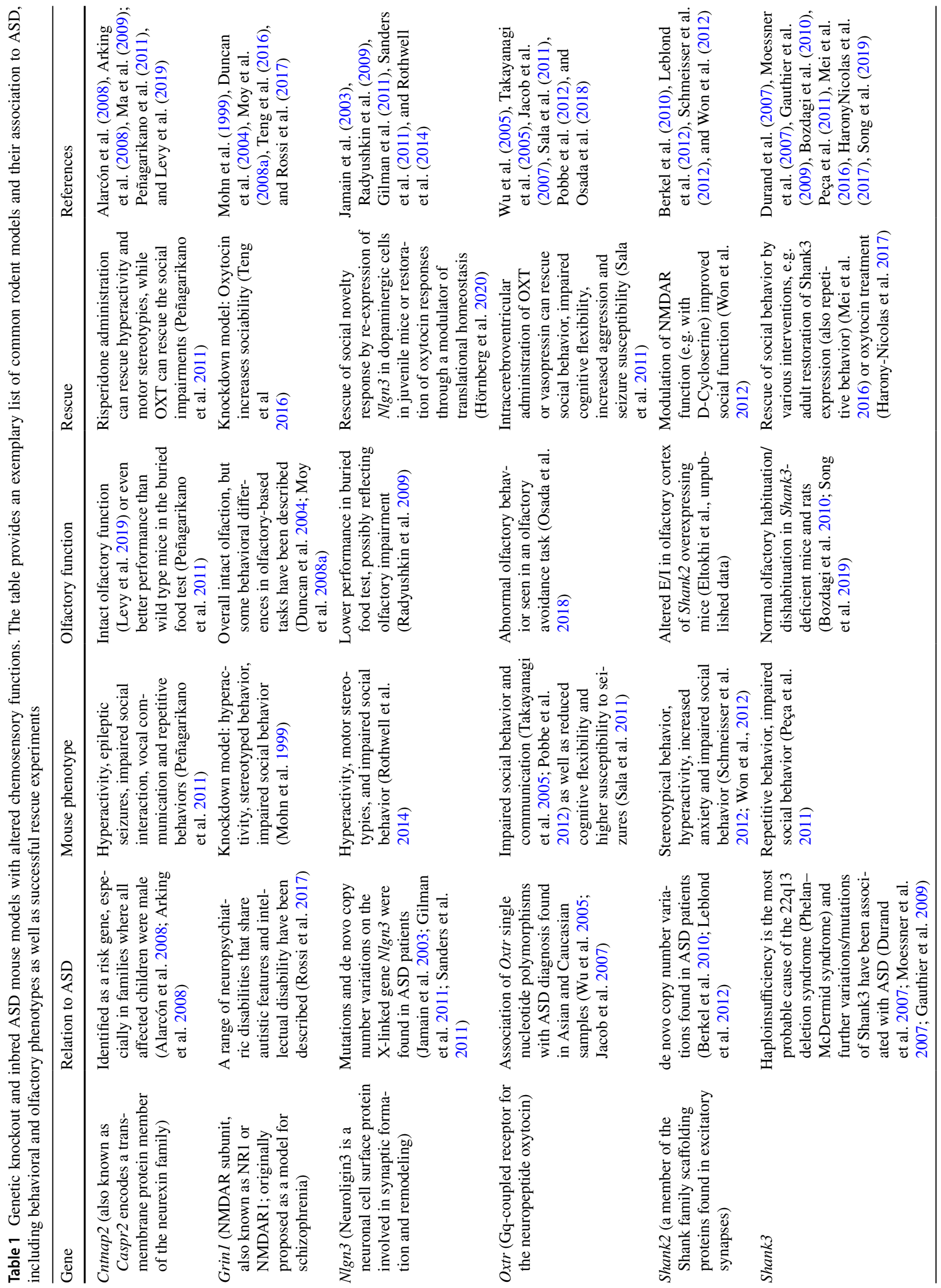




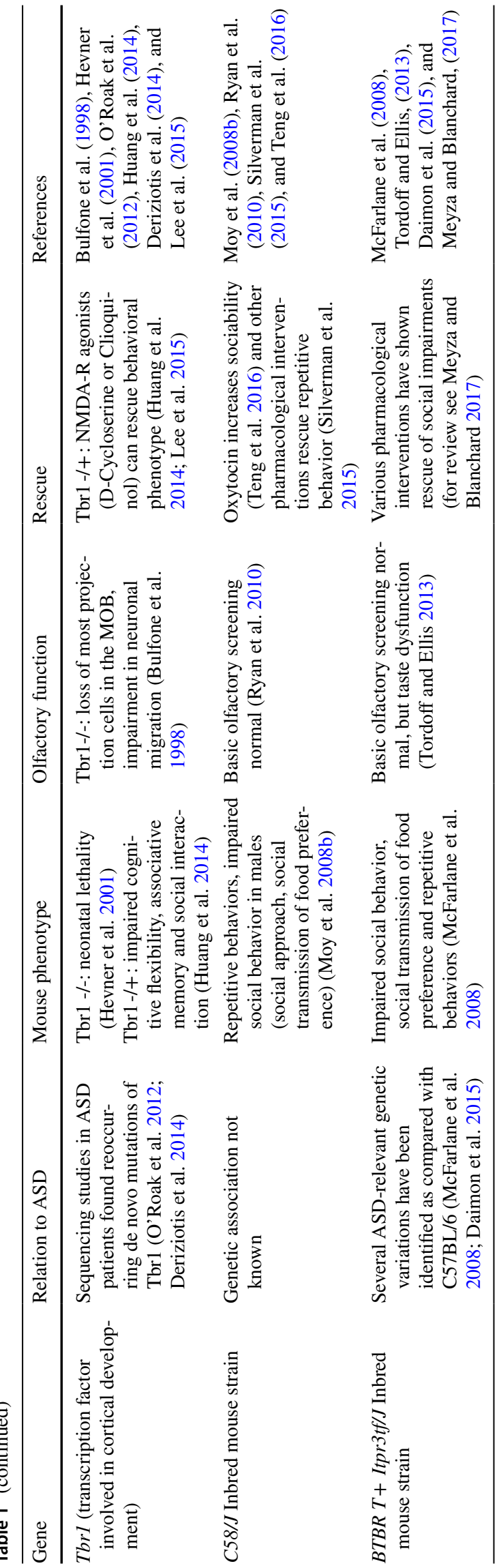

Wang et al. 2020). The acquisition of socially transmitted food preferences in this case was mediated by specialized OSNs, expressing a specific receptor unit, namely, guanylyl cyclase, which binds breath odorants. The circuitry processing social odor information is, therefore, selective to stimuli at the initial level of odorant binding. However, even with this selectivity, the processing of social odor information cannot simply be split into "social" and "non-social," without also considering how sensory processing is modulated by one's internal state (e.g., containing previous experiences, recognition) in a contextual manner to correctly extract the social information (Chen and Hong 2018).

Social behavior requires state- and context-dependent extraction and evaluation of social information from a rich multisensory input consisting of both social and non-social, relevant and irrelevant features. Examining distributed circuitry has revealed, in humans, the involvement of not only primary sensory processing cortices but also higher-order brain regions in appetitive and aversive olfactory learning (Gottfried et al. 2002), in encoding predictive reward value (Gottfried et al. 2003), and in odor percept formation ( $\mathrm{Li}$ et al. 2008). With this methodological approach, the presentation of social reinforcement learning paradigms can help measure the values assigned to social odors across multiple regions.

Decoding these responses facilitates the interpretation of affective and value encoding. Social odor learning and memory is capable of modulating innate, endogenous responses to a pure sensory stimulus, coupling such processing of incoming stimuli with a learned preference and/or valence (Macrides et al. 1982; Gottfried et al. 2002). Odor-discrimination learning is supported by the hippocampus and relies on both higher-order and primary sensory cortices (Martin et al. 2007). Higher-order areas, such as the ventral hippocampus, exhibit direct projections to the AON, whereby top-down input by the hippocampus on AON modulates the processing of incoming olfactory information, especially in regard to contextual processing and stored internal representations (Aqrabawi and Kim 2018; Levinson et al. 2020). In this manner, the AON may act as a central hub between olfactory input and odor memory (Oettl et al. 2016; Linster and Kelsch 2019; Aqrabawi and Kim 2020). To this effect, the AON is necessary for the expression of behavior relevant to the social odor memory.

All in all, both external input and internal representations contribute to dynamic changes in network processing. The network for the processing of social cues encompasses distributed circuits across primary sensory and higher-level cognitive areas that interact selectively to produce flexible social behavior. 


\section{Neural processing of social odors in ASD models and patients}

Studies have examined the underlying neuronal networks afflicted by genetic mutations responsible for ASD characterization. Indeed, affected neuronal networks have resulted in impaired processing across multiple sensory input domains (Thye et al. 2018). However, here the focus is placed on olfactory decoding of social odors. Olfactorybased task impairment has been noted in many ASD animal models (Silverman et al. 2010; Won et al. 2012). Yet, similar to ASD patients, the olfactory detection threshold has been tested in some genetic mouse models and appeared preserved (Peñagarikano et al. 2011; Won et al. 2012; Levy et al. 2019; see also Table 1).

A reoccurring finding in many animal models that exhibit behavioral impairments in the social domain is a disrupted E/I balance in a group of locally connected neurons (i.e., the microcircuit) (Lee et al. 2017). This could be a comprehensive link for bridging the level of single neurons and synaptic development to the whole system and to help understand the impact of altered synaptic wiring and circuit assembly by genetic causes. It is sufficient in the prefrontal cortex (PFC) to acutely increase E/I balance in a typicallydeveloped rodent brain to induce altered social behavior (Yizhar et al. 2011). However, the underlying mechanism causing the $\mathrm{E} / \mathrm{I}$ imbalance in distributed circuits is most likely rooted in genetic control of processes at the circuit and synapse levels (see Lee et al. 2017 for comprehensive review of ASD candidate genes and E/I balance). E/I imbalance in ASD models has been observed in prefrontal circuits (Levy et al. 2019), where disrupted E/I in Cntnap2 knock-out mice was reflected by higher noise levels in spontaneous population activity. However, other examples of E/I imbalance in other brain regions (i.e., amygdala; Lin et al. 2013) support a more systemic role of E/I balance that may influence multiple functional circuits.

Functional impairments exhibited by changes in typical olfactory wiring can affect odor discrimination and perception. Such functional processing relies heavily on the anterior piriform cortex and is facilitated by its connections to the CoA and the posterior piriform cortex, which is reciprocally connected with thalamo-cortical circuitry and higher-order cortical domains, such as the orbitofrontal cortex (Wilson et al. 2006). In a previous study measuring behavioral and fMRI responses, researchers found that ASD patients had lower odor identification scores as compared with healthy controls and exhibited decreased BOLD signal in the anterior piriform cortex during odor stimulus processing (Koehler et al. 2018). Whole-brain studies employing fMRI, either at rest or during social stimulus processing, can provide a framework for understanding ASD impairments at the systems-level and the implication for canonical networks, such as the saliency network (Uddin and Menon 2009), in social odor processing.

Recent unpublished work (Eltokhi, Oettl, Rozov, Kelsch, Rappold, Sprengel, unpublished observations) examined the functional consequences of manipulating the expression of wild-type and human point mutations in ASD cases of the Shank $2 a$ gene and addressed olfactory coding in the AON. They observed that transgenic overexpression of the wild-type Shank $2 a$ gene in glutamatergic forebrain neurons decreased social exploration, while expression of a human point mutation of Shank $2 a$ led to higher levels of conspecific exploration than in matched controls. These social behavior phenotypes were reversed when overexpression of the genes was switched off in the adult, suggesting that contrary to other behavioral alterations that persisted, are not hard-wired neurodevelopmental processes, but accessible to adult causal interventions. These two models of Shank $2 a$ dysfunction displayed altered proteomic expressions of synaptic wiring proteins and bi-directional changes in their synaptic functions. Also, the network activity in the AON was modified in the two transgenic models. Specifically, in awake mice, background network activity was altered, and the E/I ratio of stimulus responses was changed bi-directionally. An excess of wild-type Shank2a displayed decreased social exploration and an enhanced excitatory baseline drive with more background noise in the AON, while the point mutant model with increased social approach behavior displayed an increased sparseness in AON activity with lower E/I balance than controls and higher signal-to-noise in cortical odor stimulus coding.

With ASD rodent models, genetic re-expression, optogenetic, and pharmacological techniques may be employed in attempts to rescue disrupted behavioral phenotypes. For instance, rescue of social impairments was also accomplished in a Shank3 knock-out murine model via genetic re-expression of the deleted gene (Mei et al. 2016). The evidence for the role of Shank genes in ASD is growing along with attempts at selectively targeting genes for therapeutic treatment. This hints that the changes induced by genetic alterations are not completely hard-wired, but can be rescued by normalizing the expression of the gene that caused the alterations in social behavior (Mei et al. 2016).

Pharmacological treatments targeting the underlying molecular pathways have shown some success in mice, whereby inhibition of the ERK signaling pathway resulted in rescuing the pathophysiology and behavioral phenotype associated with 16p11.2 chromosomal deletion (Pucilowska et al. 2018). Pharmacological intervention in human cases may also be possible. For instance, with the pro-social neuro-hormone oxytocin that drives social stimulus processing in the brain, but its release is reduced in autism models (Peñagarikano et al. 2015; Sgritta et al. 2019; Resendez et al. 
2020), and potentially also in human ASD cases (Husarova et al. 2016; Rutigliano et al. 2016; Zhang et al. 2016).

Oxytocin is produced in the paraventricular nucleus (PVN) of the hypothalamus and released by neurons projecting to several brain regions, including primary olfactory regions (Yu et al. 1996; Choe et al. 2015; Oettl et al. 2016), the cortical amygdala (Knobloch et al. 2012), and the dorsal hippocampus (Tirko et al. 2018) (see Fig. 2). There is a tight relationship between the oxytocin and reward pathways (Dölen et al. 2013; Hung et al. 2017; Walum and Young 2018), whereby this interplay can greatly influence social behavior, reward, and value assignment. Oxytocin has been shown to influence E/I balance in higher-order brain regions, such as the hippocampus (Owen et al. 2013) and also to modify the signal-to-noise ratio for odors in the MOB through increased top-down inputs from the AON (Oettl et al. 2016; Oettl and Kelsch 2018). Electrophysiological recordings of oxytocin neurons in rats have shown activation during social interaction in an open field and selective manipulation of oxytocinergic activity, using a chemogenetic intervention, controlled motivation for social behavior (Tang et al. 2020). A different study using in-vivo 2-photon microscopy in head-fixed mice exhibited increased activity of oxytocin neurons to a social odor, specifically that of a juvenile animal (Resendez et al. 2020).

However, an immunohistological investigation revealed significantly lower numbers of immunopositive oxytocin cells in the paraventricular nucleus of the hypothalamus (PVN) in Shank3b and Cntnap2 mutant mice (Peñagarikano et al. 2015; Sgritta et al. 2019; Resendez et al. 2020). Could oxytocin (or related neuromodulators), therefore, act as social boosters to enhance or restore social information perception, and potentially serve as an ASD treatment (Young and Barrett 2015)?. This may be possible since bi-directionally modifying oxytocin release and actions in the AON resulted respectively in gain and loss of function in social exploration and memory formation of conspecifics (Oettl et al. 2016).

This question was addressed in animal models of ASD by performing rescue experiments, where oxytocin was administered to see if it would restore the healthy behavioral phenotype. Shank $3 b$ knockout mice showed decreased sociability in a 3-chamber test (Peça et al. 2011), but the social deficits could be reversed by acute intraperitoneal injection of an oxytocin receptor agonist (Resendez et al. 2020). Intracerebroventricular infusion of oxytocin in a Shank3 deficient rat model reversed the deficit in long-term social memory and also improved attention in a non-social task (Harony-Nicolas et al. 2017).

In Cntnap 2 knockout mice, acute oxytocin release using a chemo-genetic intervention showed rescue of social deficits in the sociability and reciprocal social interaction tests (Peñagarikano et al. 2015). Further, studies using two different models for ASD, C58/J and Grinl, showed increased sociability for up to 2 weeks after sub-chronic oxytocin treatment (Teng et al. 2016). A different study investigating the effect of long-term exposure to intranasally administered oxytocin in another mouse model of ASD (BTBR T+Itpr3tf/J inbred strain) only found increased female sniffing in the 3-chamber test, but no effect on other ASD-related behavior (Bales et al. 2014). Oxytocin also mediates the influence of the microbiome on social behaviors (Sherwin et al. 2019). Ingestion of Lactobacillus reuteri, a bacterial species found in the gut system (Britton 2017), leads to a behavioral rescue across a variety of genetic, environmental, and idiopathic ASD models (Sgritta et al. 2019). The change in social behavior was dependent on an intact vagus nerve and absent in animals lacking the oxytocin receptor in dopaminergic neurons of the ventral tegmental area (Sgritta et al. 2019). Also, restoration of oxytocin-signaling in the dopaminergic neurons rescued social novelty responses in Nlgn3mice (Hörnberg et al. 2020). These examples from animal experiments show that oxytocin can increase sociability and social cognition across different genetic ASD models. In parallel to the observed disruption of the E/I balance in mouse models of ASD, oxytocin modifies the $\mathrm{E} / \mathrm{I}$ ratio across sensory and higher-order brain circuits to influence social behavior.

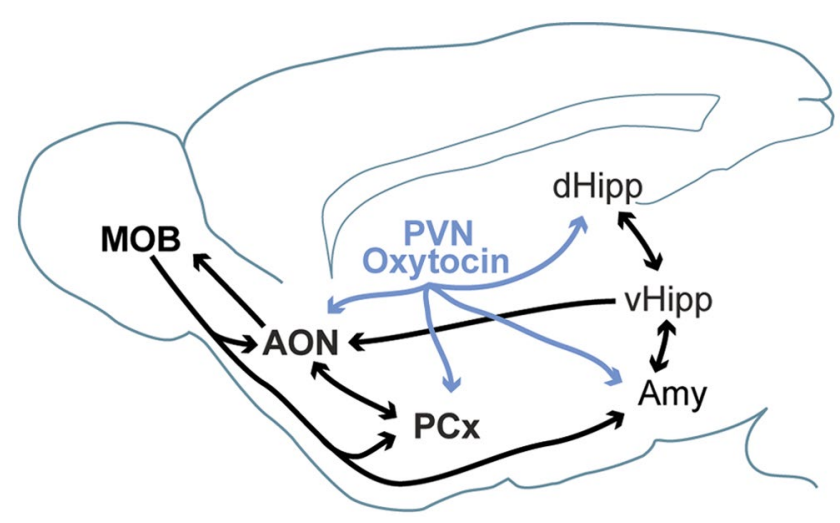

Fig. 2 Primary circuit wiring for olfaction and oxytocin. The primary olfactory processing circuitry is depicted alongside oxytocin projection sites. Incoming stimuli (e.g., social odorants) are first processed by the MOB before relay to the AON, PCx, and the Amy. Recurrent projections between bottom-up and top-down processing streams are illustrated by the double-sided arrows. The central hub for oxytocin production, the PVN, is shown projecting to downstream effector targets that can have a direct or indirect effect on olfactory processing. Abbreviations: AMY amygdala; AON anterior olfactory nucleus; dHipp and vHipp the dorsal and ventral hippocampus, respectively; MOB: main olfactory bulb; PCx piriform cortex; PVN paraventricular nucleus of the hypothalamus 


\section{Future directions}

A further examination of disrupted brain networks in ASD is required to fully understand the underlying patho-mechanisms. While a finite number of appropriate tests exists, it is nonetheless of principle importance that behavioral deficits are properly evaluated to the extent warranted. This calls for future studies employing multimodal methodology (i.e., molecular, cellular, and systemswide) to unravel impaired behavioral phenotypes throughout the biological framework. Ascribing behavioral phenotypes to specific genes may further help to predict and localize deficits.

Neuronal activity underlying social odor processing may be captured using multi-site extracellular recordings, where the coherence of activity between stimulus processing hubs can be determined. Such data are rich in the sense of temporal resolution and could be complemented with a whole-brain approach (e.g., fMRI) for systems-level decoding of olfactory processing. Prior human fMRI findings, for example, could serve as a reference for executing similar experiments in animals where in vivo cell recording is also permitted, incorporating another facet of data collection. Moreover, the development of promising non-human primate models for ASD (Bauman and Schumann 2018; Tu et al. 2019) may contribute to translating a repertoire of animal research to humans.

Considerations of both brain and body states should be taken into account in order to appropriately decode neuronal responses to social cues. Concurrent measurements of physiological parameters may help elucidate state-specific responses during social information processing. Insofar, physiological parameters may serve as another therapeutic target (Garfinkel et al. 2016). Here, clinical intervention can incorporate focused breathing and interoceptive feedback into patient care (Schauder et al. 2015).

Further, exploiting the inter-connectedness of oxytocin with the olfactory and reward learning systems may assist with typical processing of salient social stimuli. Notably, social memories affect odor discrimination and identification as well as the contextual cues and associations constituting odor percepts. Therefore, consideration of the recurrency between higher-order processing hubs and primary olfactory processing regions is vital to understanding the extent of ASD patho-mechanisms and their effects at the systems-level.

\section{Conclusion}

In conclusion, olfactory processing influences social behaviors profoundly in rodents and in humans. Therefore, it is to no surprise that ASD also displays impairments in the olfactory system. Here, we compared social odor processing in healthy individuals and in ASD and described some of the current known influences of ASD-related genes on functional encoding in the social sensory domain. The current relatively small number of neurophysiology studies suggest alterations in the E/I ratio as a recurring signature in genetic disease models and is shared in primary sensory areas and not limited to higher-order cortices. This resonates well with the finding that ASD also shows impairments in early sensory perception as well as higher cognitive domains. A large number of the identified risk genes for ASD play a role in the assembly and maintenance of synapses. The disrupted E/I balance observed in ASD models might therefore be an indirect reflection of the genetic impairment of synaptic organization. Yet, other more specific alterations in coding need to be identified since the increased E/I signature is also found in other psychiatric disorders like schizophrenia or depression.

In light of the need for developing therapeutic targets in ASD, genetic, pharmacological, and technical manipulations emerge as entry points for ASD phenotype rescue. Hope for novel treatment options also lies in the findings of recent studies that have achieved phenotype rescue by restoring correct genetic expression of autism candidate genes, such as members of the Shank family in adult rodents. Further, the potential role of neuro-hormones, such as oxytocin, in ameliorating impaired social olfactory processing was highlighted as one potential therapeutic target. Because oxytocin has also been shown to modulate E/I ratio and signal-to-noise across brain areas, it might further provide a comprehensive link to better understand social processing in health and patients.

Funding Open Access funding enabled and organized by Projekt DEAL. The work was funded by the German Ministry of Education and Research (BMBF) grant n. 01GQ1708 (WK) and the Focus Program Translational Neurosciences (RH). MJS was supported by the Care for Rare Foundation, the Eva Luise and Horst Köhler Foundation, the Else Kröner Fresenius Foundation (2018_A78), the Volkswagen Foundation and the BMBF (GeNeRARe; 01GM1519A).

\section{Compliance with ethical standards}

Conflict of interest The authors declare that they have no competing interests.

Ethical approval This article does not contain any studies with human participants or animals performed by any of the authors.

Open Access This article is licensed under a Creative Commons Attribution 4.0 International License, which permits use, sharing, adaptation, distribution and reproduction in any medium or format, as long as you give appropriate credit to the original author(s) and the source, provide a link to the Creative Commons licence, and indicate if changes 
were made. The images or other third party material in this article are included in the article's Creative Commons licence, unless indicated otherwise in a credit line to the material. If material is not included in the article's Creative Commons licence and your intended use is not permitted by statutory regulation or exceeds the permitted use, you will need to obtain permission directly from the copyright holder. To view a copy of this licence, visit http://creativecommons.org/licenses/by/4.0/.

\section{References}

Addo RN, Wiens S, Nord M, Larsson M (2017) Olfactory functions in adults with autism spectrum disorders. Perception 46:530-537. https://doi.org/10.1177/0301006616686100

Alarcón M, Abrahams BS, Stone JL et al (2008) Linkage, association, and gene-expression analyses identify CNTNAP2 as an autismsusceptibility gene. Am J Hum Genet 82:150-159. https://doi. org/10.1016/j.ajhg.2007.09.005

American Psychiatric Association (2013) Diagnostic and Statistical Manual of Mental Disorders (DSM-5). American Psychiatric Pub

Aqrabawi AJ, Kim JC (2018) Hippocampal projections to the anterior olfactory nucleus differentially convey spatiotemporal information during episodic odour memory. Nat Commun 9:2735. https://doi. org/10.1038/s41467-018-05131-6

Aqrabawi AJ, Kim JC (2020) Olfactory memory representations are stored in the anterior olfactory nucleus. Nat Commun 11:1246. https://doi.org/10.1038/s41467-020-15032-2

Arking DE, Cutler DJ, Brune CW et al (2008) A common genetic variant in the neurexin superfamily member CNTNAP2 increases familial risk of autism. Am J Hum Genet 82:160-164. https://doi. org/10.1016/j.ajhg.2007.09.015

Auer TO, Khallaf MA, Silbering AF et al (2020) Olfactory receptor and circuit evolution promote host specialization. Nature 579:402408. https://doi.org/10.1038/s41586-020-2073-7

Autism and Developmental Disabilities Monitoring Network Surveillance Year 2002 Principal Investigators; Centers for Disease Control and Prevention. Prevalence of autism spectrum disorders--autism and developmental disabilities monitoring network, 14 sites, United States, 2002. MMWR Surveill Summ. 2007 Feb 9;56(1):12-28. PMID: 17287715

Bales KL, Solomon M, Jacob S et al (2014) Long-term exposure to intranasal oxytocin in a mouse autism model. Transl Psychiatry 4:e480-e480. https://doi.org/10.1038/tp.2014.117

Barros F, Soares SC (2020) Giving meaning to the social world in autism spectrum disorders: olfaction as a missing piece of the puzzle? Neurosci Biobehav Rev 116:239-250. https://doi. org/10.1016/j.neubiorev.2020.06.008

Baum MJ, Kelliher KR (2009) Complementary roles of the main and accessory olfactory systems in mammalian mate recognition. Annu Rev Physiol 71:141-160. https://doi.org/10.1146/annurev. physiol.010908.163137

Bauman MD, Schumann CM (2018) Advances in nonhuman primate models of autism: integrating neuroscience and behavior. Exp Neurol 299:252-265. https://doi.org/10.1016/j.expneurol.2017.07.021

Bennetto L, Kuschner ES, Hyman SL (2007) Olfaction and taste processing in autism. Biol Psychiat 62:1015-1021. https://doi. org/10.1016/j.biopsych.2007.04.019

Berkel S, Marshall CR, Weiss B et al (2010) Mutations in the SHANK2 synaptic scaffolding gene in autism spectrum disorder and mental retardation. Nat Genet 42:489-491. https://doi.org/10.1038/ ng.589

Bey AL, Wang X, Yan H et al (2018) Brain region-specific disruption of Shank3 in mice reveals a dissociation for cortical and striatal circuits in autism-related behaviors. Transl Psychiatry 8:1-17. https://doi.org/10.1038/s41398-018-0142-6
Boudjarane MA, Grandgeorge M, Marianowski R et al (2017) Perception of odors and tastes in autism spectrum disorders: a systematic review of assessments. Autism Research 10:10451057. https://doi.org/10.1002/aur.1760

Bourgeron T (2015) From the genetic architecture to synaptic plasticity in autism spectrum disorder. Nat Rev Neurosci 16:551-563. https://doi. org/10.1038/nrn3992

Boyd AM, Kato HK, Komiyama T, Isaacson JS (2015) Broadcasting of cortical activity to the olfactory bulb. Cell Rep 10:10321039. https://doi.org/10.1016/j.celrep.2015.01.047

Boyd AM, Sturgill JF, Poo C, Isaacson JS (2012) Cortical feedback control of olfactory bulb circuits. Neuron 76:1161-1174. https:// doi.org/10.1016/j.neuron.2012.10.020

Bozdagi O, Sakurai T, Papapetrou D et al (2010) Haploinsufficiency of the autism-associated Shank3 gene leads to deficits in synaptic function, social interaction, and social communication. Mol Autism 1:15. https://doi.org/10.1186/2040-2392-1-15

Brann DH, Datta SR (2020) Finding the brain in the nose. Annu Rev Neurosci 43:277-295. https://doi.org/10.1146/annurev-neuro102119-103452

Britton RA (2017) Chapter 8 - Lactobacillus reuteri. In: Floch MH, Ringel Y, Allan Walker W (eds) The microbiota in gastrointestinal pathophysiology. Academic Press, Boston, pp 89-97

Bulfone A, Wang F, Hevner R et al (1998) An olfactory sensory map develops in the absence of normal projection neurons or GABAergic interneurons. Neuron 21:1273-1282

Cermak SA, Curtin C, Bandini LG (2010) Food selectivity and sensory sensitivity in children with autism spectrum disorders. J Am Diet Assoc 110:238-246. https://doi.org/10.1016/j. jada.2009.10.032

Chamero P, Katsoulidou V, Hendrix P et al (2011) G protein Goo is essential for vomeronasal function and aggressive behavior in mice. PNAS 108:12898-12903. https://doi.org/10.1073/ pnas. 1107770108

Chamero P, Marton TF, Logan DW et al (2007) Identification of protein pheromones that promote aggressive behaviour. Nature 450:899 902. https://doi.org/10.1038/nature05997

Chen P, Hong W (2018) Neural circuit mechanisms of social behavior. Neuron 98:16-30. https://doi.org/10.1016/j.neuron.2018.02.026

Choe HK, Reed MD, Benavidez N et al (2015) Oxytocin mediates entrainment of sensory stimuli to social cues of opposing valence. Neuron 87:152-163. https://doi.org/10.1016/j.neuron.2015.06.022

Clancy AN, Coquelin A, Macrides F et al (1984) Sexual behavior and aggression in male mice: involvement of the vomeronasal system. J Neurosci 4:2222-2229. https://doi.org/10.1523/JNEUROSCI.0409-02222.1984

Daimon CM, Jasien JM, Wood WHI et al (2015) Hippocampal transcriptomic and proteomic alterations in the BTBR mouse model of autism spectrum disorder. Front Physiol 6. https://doi. org/10.3389/fphys.2015.00324

de la Torre-Ubieta L, Won H, Stein JL, Geschwind DH (2016) Advancing the understanding of autism disease mechanisms through genetics. Nat Med 22:345-361. https://doi.org/10.1038/ nm.4071

De Rubeis S, Buxbaum JD (2015) Genetics and genomics of autism spectrum disorder: embracing complexity. Hum Mol Genet 24:R24-R31. https://doi.org/10.1093/hmg/ddv273

Deriziotis P, O'Roak BJ, Graham SA et al (2014) De novo TBR1 mutations in sporadic autism disrupt protein functions. Nat Commun 5:4954. https://doi.org/10.1038/ncomms5954

Dölen G, Darvishzadeh A, Huang KW, Malenka RC (2013) Social reward requires coordinated activity of nucleus accumbens oxytocin and serotonin. Nature 501:179-184. https://doi. org/10.1038/nature12518

Duncan GE, Moy SS, Perez A et al (2004) Deficits in sensorimotor gating and tests of social behavior in a genetic model of reduced NMDA 
receptor function. Behav Brain Res 153:507-519. https://doi. org/10.1016/j.bbr.2004.01.008

Durand CM, Betancur C, Boeckers TM et al (2007) Mutations in the gene encoding the synaptic scaffolding protein SHANK3 are associated with autism spectrum disorders. Nat Genet 39:25-27. https://doi.org/10.1038/ng1933

Endevelt-Shapira Y, Perl O, Ravia A et al (2018) Altered responses to social chemosignals in autism spectrum disorder. Nat Neurosci 21:111-119. https://doi.org/10.1038/s41593-017-0024-x

Ey E, Bourgeron T, Boeckers TM et al (2020) Editorial: Shankopathies: shank protein deficiency-induced synaptic diseases. Front Mol Neurosci 13.https://doi.org/10.3389/fnmol.2020.00011

Fernandez A, Meechan DW, Karpinski BA et al (2019) Mitochondrial dysfunction leads to cortical under-connectivity and cognitive impairment. Neuron 102:1127-1142.e3. https:// doi.org/10.1016/j.neuron.2019.04.013

Frumin I, Perl O, Endevelt-Shapira Y, et al (2015) A social chemosignaling function for human handshaking. eLife 4:e05154. https://doi.org/10.7554/eLife.05154

Galle SA, Courchesne V, Mottron L, Frasnelli J (2013) Olfaction in the autism spectrum. Perception. https://doi.org/10.1068/p7337

Garfinkel SN, Tiley C, O'Keeffe S et al (2016) Discrepancies between dimensions of interoception in autism: implications for emotion and anxiety. Biol Psychol 114:117-126. https:// doi.org/10.1016/j.biopsycho.2015.12.003

Gauthier J, Spiegelman D, Piton A et al (2009) Novel de novo SHANK3 mutation in autistic patients. Am J Med Genet B Neuropsychiatr Genet 150B:421-424. https://doi.org/10.1002/ ajmg.b. 30822

Gilman SR, Iossifov I, Levy D et al (2011) Rare de novo variants associated with autism implicate a large functional network of genes involved in formation and function of synapses. Neuron 70:898-907. https://doi.org/10.1016/j.neuron.2011.05.021

Gliga T, Bedford R, Charman T et al (2015) Enhanced visual search in infancy predicts emerging autism symptoms. Curr Biol 25:1727-1730. https://doi.org/10.1016/j.cub.2015.05.011

Golden CE, Buxbaum JD, De Rubeis S (2018) Disrupted circuits in mouse models of autism spectrum disorder and intellectual disability. Curr Opin Neurobiol 48:106-112. https://doi. org/10.1016/j.conb.2017.11.006

Gottfried JA, O'Doherty J, Dolan RJ (2002) Appetitive and aversive olfactory learning in humans studied using event-related functional magnetic resonance imaging. J Neurosci 22:10829-10837. https:// doi.org/10.1523/JNEUROSCI.22-24-10829.2002

Gottfried JA, O'Doherty J, Dolan RJ (2003) Encoding predictive reward value in human amygdala and orbitofrontal cortex. Science 301:1104-1107. https://doi.org/10.1126/science. 1087919

Grabrucker AM, Schmeisser MJ, Schoen M, Boeckers TM (2011) Postsynaptic ProSAP/Shank scaffolds in the cross-hair of synaptopathies. Trends Cell Biol 21:594-603. https://doi. org/10.1016/j.tcb.2011.07.003

Guilmatre A, Huguet G, Delorme R, Bourgeron T (2014) The emerging role of SHANK genes in neuropsychiatric disorders. Dev Neurobiol 74:113-122. https://doi.org/10.1002/dneu.22128

Guo D, Peng Y, Wang L et al (2019) Autism-like social deficit generated by Dock4 deficiency is rescued by restoration of Rac1 activity and NMDA receptor function. Mol Psychiatry 1-15. https://doi.org/10.1038/s41380-019-0472-7

Harony-Nicolas H, Kay M, du Hoffmann J et al (2017) Oxytocin improves behavioral and electrophysiological deficits in a novel Shank3-deficient rat. eLife 6:e18904. https://doi.org/10.7554/ eLife. 18904

Hevner RF, Shi L, Justice N et al (2001) Tbr1 regulates differentiation of the preplate and layer 6 . Neuron 29:353-366. https://doi. org/10.1016/S0896-6273(01)00211-2
Heymann EW (2006) The neglected sense-olfaction in primate behavior, ecology, and evolution. Am J Primatol 68:519-524. https://doi.org/10.1002/ajp.20249

Holy TE (2018) The accessory olfactory system: innately specialized or microcosm of mammalian circuitry? Annu Rev Neurosci 41:501525. https://doi.org/10.1146/annurev-neuro-080317-061916

Hörnberg H, Pérez-Garci E, Schreiner D et al (2020) Rescue of oxytocin response and social behaviour in a mouse model of autism. Nature 584:252-256. https://doi.org/10.1038/ s41586-020-2563-7

Huang TN, Chuang HC, Chou WH et al (2014) Tbr1 haploinsufficiency impairs amygdalar axonal projections and results in cognitive abnormality. Nat Neurosci 17:240-247. https://doi.org/10.1038/ nn. 3626

Hung LW, Neuner S, Polepalli JS et al (2017) Gating of social reward by oxytocin in the ventral tegmental area. Science 357:14061411. https://doi.org/10.1126/science.aan4994

Husarova VM, Lakatosova S, Pivovarciova A et al (2016) Plasma oxytocin in children with autism and its correlations with behavioral parameters in children and parents. Psychiatry Investig 13:174-183. https://doi.org/10.4306/pi.2016.13.2.174

Imai T, Sakano H (2007) Roles of odorant receptors in projecting axons in the mouse olfactory system. Curr Opin Neurobiol 17:507-515. https://doi.org/10.1016/j.conb.2007.08.002

Jacob S, Brune CW, Carter CS et al (2007) Association of the oxytocin receptor gene (OXTR) in Caucasian children and adolescents with autism. Neurosci Lett 417:6-9. https://doi.org/10.1016/j. neulet.2007.02.001

Jamain S, Quach H, Betancur C et al (2003) Mutations of the X-linked genes encoding neuroligins NLGN3 and NLGN4 are associated with autism. Nat Genet 34:27-29. https://doi.org/10.1038/ng1136

Jansen AG, Dieleman GC, Jansen PR et al (2020) Psychiatric polygenic risk scores as predictor for attention deficit/ hyperactivity disorder and autism spectrum disorder in a clinical child and adolescent sample. Behav Genet 50:203-212. https://doi.org/10.1007/s10519-019-09965-8

Jiang Y, Ehlers MD (2013) Modeling autism by SHANK gene mutations in mice. Neuron 78:8-27. https://doi.org/10.1016/j.neuron.2013.03.016

Kaldy Z, Kraper C, Carter AS, Blaser E (2011) Toddlers with autism spectrum disorder are more successful at visual search than typically developing toddlers. Dev Sci 14:980-988. https://doi. org/10.1111/j.1467-7687.2011.01053.x

Keller M, Douhard Q, Baum MJ, Bakker J (2006) Destruction of the main olfactory epithelium reduces female sexual behavior and olfactory investigation in female mice. Chem Senses 31:315-323. https://doi.org/10.1093/chemse/bjj035

Kern JK, Trivedi MH, Garver CR et al (2006) The pattern of sensory processing abnormalities in autism. Autism 10:480-494. https:// doi.org/10.1177/1362361306066564

Kim R, Kim J, Chung C et al (2018) Cell-type-specific Shank2 deletion in mice leads to differential synaptic and behavioral phenotypes. J Neurosci 38:4076-4092. https://doi.org/10.1523/JNEUROSCI. 2684-17.2018

Kim Y, Venkataraju KU, Pradhan K et al (2015) Mapping social behaviorinduced brain activation at cellular resolution in the mouse. Cell Rep 10:292-305. https://doi.org/10.1016/j.celrep.2014.12.014

Knobloch HS, Charlet A, Hoffmann LC et al (2012) Evoked axonal oxytocin release in the central amygdala attenuates fear response. Neuron 73:553-566. https://doi.org/10.1016/j.neuron. 2011.11.030

Koehler L, Fournel A, Albertowski K et al (2018) Impaired odor perception in autism spectrum disorder is associated with decreased activity in olfactory cortex. Chem Senses 43:627-634. https://doi.org/10.1093/chemse/bjy051 
Kollo M, Schmaltz A, Abdelhamid M et al (2014) "Silent" mitral cells dominate odor responses in the olfactory bulb of awake mice. Nat Neurosci 17:1313-1315. https://doi.org/10.1038/nn.3768

Krusemark EA, Novak LR, Gitelman DR, Li W (2013) When the sense of smell meets emotion: anxiety-state-dependent olfactory processing and neural circuitry adaptation. J Neurosci 33:15324 15332. https://doi.org/10.1523/JNEUROSCI.1835-13.2013

Larsson M, Tirado C, Wiens S (2017) A meta-analysis of odor thresholds and odor identification in autism spectrum disorders. Front Psychol 8.https://doi.org/10.3389/fpsyg.2017.00679

Leblond CS, Heinrich J, Delorme R et al (2012) Genetic and functional analyses of SHANK2 mutations suggest a multiple hit model of autism spectrum disorders. PLoS Genet 8:e1002521. https://doi. org/10.1371/journal.pgen.1002521

Lee E, Lee J, Kim E (2017) Excitation/inhibition imbalance in animal models of autism spectrum disorders. Biol Psychiat 81:838-847. https://doi.org/10.1016/j.biopsych.2016.05.011

Lee EJ, Lee H, Huang TN et al (2015) Trans-synaptic zinc mobilization improves social interaction in two mouse models of autism through NMDAR activation. Nat Commun 6:7168. https://doi. org/10.1038/ncomms8168

Lee S, Lee E, Kim R et al (2018) Shank2 deletion in parvalbumin neurons leads to moderate hyperactivity, enhanced self-grooming and suppressed seizure susceptibility in mice. Front Mol Neurosci 11. https://doi.org/10.3389/fnmol.2018.00209

Lepousez G, Nissant A, Bryant AK et al (2014) Olfactory learning promotes input-specific synaptic plasticity in adult-born neurons. Proc Natl Acad Sci USA 111:13984-13989. https:// doi.org/10.1073/pnas.1404991111

Levinson M, Kolenda JP, Alexandrou GJ et al (2020) Context-dependent odor learning requires the anterior olfactory nucleus. Behav Neurosci 134:332-343. https://doi.org/10.1037/bne0000371

Levy DR, Tamir T, Kaufman M et al (2019) Dynamics of social representation in the mouse prefrontal cortex. Nat Neurosci 22:2013-2022. https://doi.org/10.1038/s41593-019-0531-z

Leypold BG, Yu CR, Leinders-Zufall T et al (2002) Altered sexual and social behaviors in trp2 mutant mice. PNAS 99:6376-6381. https:// doi.org/10.1073/pnas.082127599

Li W, Howard JD, Parrish TB, Gottfried JA (2008) Aversive learning enhances perceptual and cortical discrimination of indiscriminable odor cues. Science 319:1842-1845. https://doi. org/10.1126/science.1152837

Liberles SD (2014) Mammalian pheromones. Annu Rev Physiol 76:151175. https://doi.org/10.1146/annurev-physiol-021113-170334

Lin HC, Gean PW, Wang CC et al (2013) The amygdala excitatory/ inhibitory balance in a valproate-induced rat autism model. PLoS ONE 8:e55248. https://doi.org/10.1371/journal.pone.0055248

Linster C, Kelsch W (2019) A Computational Model of Oxytocin Modulation of Olfactory Recognition Memory. eNeuro 6:. https ://doi.org/10.1523/ENEURO.0201-19.2019

Ma D, Salyakina D, Jaworski JM et al (2009) A genome-wide association study of autism reveals a common novel risk locus at 5p14.1. Ann Hum Genet 73:263-273. https://doi. org/10.1111/j.1469-1809.2009.00523.x

Macrides F, Eichenbaum HB, Forbes WB (1982) Temporal relationship between sniffing and the limbic theta rhythm during odor discrimination reversal learning. J Neurosci 2:1705-1717. https:// doi.org/10.1523/JNEUROSCI.02-12-01705.1982

Margrie TW, Sakmann B, Urban NN (2001) Action potential propagation in mitral cell lateral dendrites is decremental and controls recurrent and lateral inhibition in the mammalian olfactory bulb. Proc Natl Acad Sci USA 98:319-324. https:// doi.org/10.1073/pnas.011523098

Marín O (2012) Interneuron dysfunction in psychiatric disorders. Nat Rev Neurosci 13:107-120. https://doi.org/10.1038/nrn3155
Markopoulos F, Rokni D, Gire DH, Murthy VN (2012) Functional properties of cortical feedback projections to the olfactory bulb. Neuron 76:1175-1188. https://doi.org/10.1016/j.neuron.2012.10.028

Martin C, Beshel J, Kay LM (2007) An olfacto-hippocampal network is dynamically involved in odor-discrimination learning. J Neurophysiol 98:2196-2205. https://doi.org/10.1152/jn. 00524.2007

McFarlane HG, Kusek GK, Yang M et al (2008) Autism-like behavioral phenotypes in BTBR $\mathrm{T}+\mathrm{tf} / \mathrm{J}$ mice. Genes Brain Behav 7:152-163. https://doi.org/10.1111/j.1601183X.2007.00330.X

McKlveen JM, Moloney RD, Scheimann JR et al (2019) "Braking" the prefrontal cortex: the role of glucocorticoids and interneurons in stress adaptation and pathology. Biol Psychiat 86:669-681. https:// doi.org/10.1016/j.biopsych.2019.04.032

Mei Y, Monteiro P, Zhou Y et al (2016) Adult restoration of Shank3 expression rescues selective autistic-like phenotypes. Nature 530:481-484. https://doi.org/10.1038/nature16971

Meyza KZ, Blanchard DC (2017) The BTBR mouse model of idiopathic autism-current view on mechanisms. Neurosci Biobehav Rev 76:99-110. https://doi.org/10.1016/j.neubiorev. 2016.12.037

Moessner R, Marshall CR, Sutcliffe JS et al (2007) Contribution of SHANK3 mutations to autism spectrum disorder. Am J Hum Genet 81:1289-1297. https://doi.org/10.1086/522590

Mohn AR, Gainetdinov RR, Caron MG, Koller BH (1999) Mice with reduced NMDA receptor expression display behaviors related to schizophrenia. Cell 98:427-436. https://doi. org/10.1016/S0092-8674(00)81972-8

Mombaerts P (2006) Axonal wiring in the mouse olfactory system. Annu Rev Cell Dev Biol 22:713-737. https://doi.org/10.1146/ annurev.cellbio.21.012804.093915

Mombaerts P, Wang F, Dulac C et al (1996) Visualizing an olfactory sensory map. Cell 87:675-686

Monteiro P, Feng G (2017) SHANK proteins: roles at the synapse and in autism spectrum disorder. Nat Rev Neurosci 18:147-157. https:// doi.org/10.1038/nrn.2016.183

Moy SS, Nadler JJ, Poe MD et al (2008a) Development of a mouse test for repetitive, restricted behaviors: relevance to autism. Behav Brain Res 188:178-194. https://doi.org/10.1016/j. bbr.2007.10.029

Moy SS, Nadler JJ, Young NB et al (2008b) Social approach and repetitive behavior in eleven inbred mouse strains. Behav Brain Res 191:118-129. https://doi.org/10.1016/j.bbr.2008.03.015

Muhle RA, Reed HE, Stratigos KA, Veenstra-VanderWeele J (2018) The emerging clinical neuroscience of autism spectrum disorder: a review. JAMA Psychiatry 75:514-523. https://doi.org/10.1001/ jamapsychiatry.2017.4685

Munger SD, Leinders-Zufall T, McDougall LM et al (2010) An olfactory subsystem that detects carbon disulfide and mediates food-related social learning. Curr Biol 20:1438-1444. https:// doi.org/10.1016/j.cub.2010.06.021

Muratori F, Tonacci A, Billeci L et al (2017) Olfactory processing in male children with autism: atypical odor threshold and identification. J Autism Dev Disord 47:3243-3251. https://doi. org/10.1007/s10803-017-3250-x

Oettl LL, Kelsch W (2018) Oxytocin and Olfaction. In: Hurlemann R, Grinevich V (eds) Behavioral pharmacology of neuropeptides: oxytocin. Springer International Publishing, Cham, pp 55-75

Oettl LL, Ravi N, Schneider M et al (2016) Oxytocin enhances social recognition by modulating cortical control of early olfactory processing. Neuron 90:609-621. https://doi.org/10.1016/j. neuron.2016.03.033

O'Roak BJ, Vives L, Fu W et al (2012) Multiplex targeted sequencing identifies recurrently mutated genes in autism spectrum disorders. Science 338:1619-1622. https://doi.org/10.1126/science.1227764 
Osada K, Ohta T, Takai R et al (2018) Oxytocin receptor signaling contributes to olfactory avoidance behavior induced by an unpleasant odorant Biology Open 7.https://doi.org/10.1242/ bio.029140

Owen SF, Tuncdemir SN, Bader PL et al (2013) Oxytocin enhances hippocampal spike transmission by modulating fast-spiking interneurons. Nature 500:458-462. https://doi.org/10.1038/nature12330

Pagani M, Bertero A, Liska A et al (2019) Deletion of autism risk gene Shank3 disrupts prefrontal connectivity. J Neurosci 39:52995310. https://doi.org/10.1523/JNEUROSCI.2529-18.2019

Pankevich DE, Baum MJ, Cherry JA (2004) Olfactory sex discrimination persists, whereas the preference for urinary odorants from estrous females disappears in male mice after vomeronasal organ removal. J Neurosci 24:9451-9457. https:// doi.org/10.1523/JNEUROSCI.2376-04.2004

Peça J, Feliciano C, Ting JT et al (2011) Shank3 mutant mice display autistic-like behaviours and striatal dysfunction. Nature 472:437442. https://doi.org/10.1038/nature09965

Peñagarikano O, Abrahams BS, Herman EI et al (2011) Absence of CNTNAP2 leads to epilepsy, neuronal migration abnormalities and core autism-related deficits. Cell 147:235-246. https://doi. org/10.1016/j.cell.2011.08.040

Peñagarikano O, Lázaro MT, Lu X-H et al (2015) Exogenous and evoked oxytocin restores social behavior in the Cntnap2 mouse model of autism. Sci Trans Med 7:271ra8-271ra8. https://doi. org/10.1126/scitranslmed.3010257

Perl O, Ravia A, Rubinson M et al (2019) Human non-olfactory cognition phase-locked with inhalation. Nat Hum Behav 3:501512. https://doi.org/10.1038/s41562-019-0556-z

Peter S, ten Brinke MM, Stedehouder J et al (2016) Dysfunctional cerebellar Purkinje cells contribute to autism-like behaviour in Shank2 -deficient mice. Nat Commun 7:12627. https://doi. org/10.1038/ncomms 12627

Pobbe RLH, Pearson BL, Defensor EB et al (2012) Oxytocin receptor knockout mice display deficits in the expression of autism-related behaviors. Horm Behav 61:436-444. https://doi.org/10.1016/j. yhbeh.2011.10.010

Pucilowska J, Vithayathil J, Pagani M, et al (2018) Pharmacological inhibition of ERK signaling rescues pathophysiology and behavioral phenotype associated with 16p11.2 chromosomal deletion in mice. J Neurosci. https://doi.org/10.1523/JNEUROSCI.0515-17.2018

Quintela RM, Bauer J, Wallhorn L et al (2020) Dynamic impairment of olfactory behavior and signaling mediated by an olfactory corticofugal system. J Neurosci 40:7269-7285. https://doi. org/10.1523/JNEUROSCI.2667-19.2020

Radyushkin K, Hammerschmidt K, Boretius S et al (2009) Neuroligin3-deficient mice: model of a monogenic heritable form of autism with an olfactory deficit. Genes Brain Behav 8:416-425. https:// doi.org/10.1111/j.1601-183X.2009.00487.x

Ravi N, Sanchez-Guardado L, Lois C, Kelsch W (2017) Determination of the connectivity of newborn neurons in mammalian olfactory circuits. Cell Mol Life Sci 74:849-867. https://doi.org/10.1007/ s00018-016-2367-y

Resendez SL, Namboodiri VKM, Otis JM et al (2020) Social stimuli induce activation of oxytocin neurons within the paraventricular nucleus of the hypothalamus to promote social behavior in male mice. J Neurosci 1515-18. https://doi.org/10.1523/ JNEUROSCI.1515-18.2020

Rinaldi T, Silberberg G, Markram H (2008) Hyperconnectivity of local neocortical microcircuitry induced by prenatal exposure to valproic acid. Cereb Cortex 18:763-770. https://doi.org/10.1093/ cercor/bhm117

Robertson CE, Baron-Cohen S (2017) Sensory perception in autism. Nat Rev Neurosci 18:671-684. https://doi.org/10.1038/ nrn.2017.112
Rosenkranz JA, Venheim ER, Padival M (2010) Chronic stress causes amygdala hyperexcitability in rodents. Biol Psychiat 67:11281136. https://doi.org/10.1016/j.biopsych.2010.02.008

Rossi M, Chatron N, Labalme A et al (2017) Novel homozygous missense variant of GRIN1 in two sibs with intellectual disability and autistic features without epilepsy. Eur J Hum Genet 25:376380. https://doi.org/10.1038/ejhg.2016.163

Rothermel M, Wachowiak M (2014) Functional imaging of cortical feedback projections to the olfactory bulb. Front Neural Circuits 8. https://doi.org/10.3389/fncir.2014.00073

Rothwell PE, Fuccillo MV, Maxeiner S et al (2014) Autism-associated neuroligin-3 mutations commonly impair striatal circuits to boost repetitive behaviors. Cell 158:198-212. https://doi.org/10.1016/j. cell.2014.04.045

Rozenkrantz L, Zachor D, Heller I et al (2015) A mechanistic link between olfaction and autism spectrum disorder. Curr Biol 25:1904-1910. https://doi.org/10.1016/j.cub.2015.05.048

Rutigliano G, Rocchetti M, Paloyelis Y et al (2016) Peripheral oxytocin and vasopressin: biomarkers of psychiatric disorders? A comprehensive systematic review and preliminary meta-analysis. Psychiatry Res 241:207-220. https://doi.org/10.1016/j.psychres.2016.04.117

Ryan BC, Young NB, Crawley JN et al (2010) Social deficits, stereotypy and early emergence of repetitive behavior in the C58/J inbred mouse strain. Behav Brain Res 208:178-188. https://doi. org/10.1016/j.bbr.2009.11.031

Sakano H (2020) Developmental regulation of olfactory circuit formation in mice. Dev Growth Differ 62:199-213. https://doi. org/10.1111/dgd.12657

Sala M, Braida D, Lentini D et al (2011) Pharmacologic rescue of impaired cognitive flexibility, social deficits, increased aggression, and seizure susceptibility in oxytocin receptor null mice: a neurobehavioral model of autism. Biol Psychiat 69:875882. https://doi.org/10.1016/j.biopsych.2010.12.022

Sanders SJ, Ercan-Sencicek AG, Hus V et al (2011) Multiple recurrent de novo CNVs, including duplications of the 7q11.23 Williams syndrome region, are strongly associated with autism. Neuron 70:863-885. https://doi.org/10.1016/j.neuron.2011.05.002

Schauder KB, Mash LE, Bryant LK, Cascio CJ (2015) Interoceptive ability and body awareness in autism spectrum disorder. $\mathrm{J}$ Exp Child Psychol 131:193-200. https://doi.org/10.1016/j. jecp.2014.11.002

Schmeisser MJ (2015) Translational neurobiology in Shank mutant mice-model systems for neuropsychiatric disorders. Ann Anat - Anatomischer Anzeiger 200:115-117. https://doi.org/10.1016/j. aanat.2015.03.006

Schmeisser MJ, Ey E, Wegener S et al (2012) Autistic-like behaviours and hyperactivity in mice lacking ProSAP1/Shank2. Nature 486:256-260. https://doi.org/10.1038/nature11015

Schreck KA, Williams K (2006) Food preferences and factors influencing food selectivity for children with autism spectrum disorders. Res Dev Disabil 27:353-363. https://doi.org/10.1016/j. ridd.2005.03.005

Selten M, van Bokhoven H, Nadif Kasri N (2018) Inhibitory control of the excitatory/inhibitory balance in psychiatric disorders. F1000Res 7:. https://doi.org/10.12688/f1000research.12155.1

Sgritta M, Dooling SW, Buffington SA et al (2019) Mechanisms underlying microbial-mediated changes in social behavior in mouse models of autism spectrum disorder. Neuron 101:246259.e6. https://doi.org/10.1016/j.neuron.2018.11.018

Sherwin E, Bordenstein SR, Quinn JL et al (2019) Microbiota and the social brain Science 366. https://doi.org/10.1126/science.aar2016

Silverman JL, Pride MC, Hayes JE et al (2015) GABA B receptor agonist R-Baclofen reverses social deficits and reduces repetitive behavior in two mouse models of autism. Neuropsychopharmacol 40:2228-2239. https://doi.org/10.1038/npp.2015.66 
Silverman JL, Yang M, Lord C, Crawley JN (2010) Behavioural phenotyping assays for mouse models of autism. Nat Rev Neurosci 11:490-502. https://doi.org/10.1038/nrn2851

Song TJ, Lan XY, Wei MP et al (2019) Altered behaviors and impaired synaptic function in a novel rat model with a complete Shank3 deletion. Front Cell Neurosci 13.https://doi. org/10.3389/fncel.2019.00111

Sung YJ, Dawson G, Munson J et al (2005) Genetic investigation of quantitative traits related to autism: use of multivariate polygenic models with ascertainment adjustment. Am J Hum Genet 76:68-81. https://doi.org/10.1086/426951

Takayanagi Y, Yoshida M, Bielsky IF et al (2005) Pervasive social deficits, but normal parturition, in oxytocin receptor-deficient mice. PNAS 102:16096-16101. https://doi.org/10.1073/pnas.0505312102

Takeuchi H, Inokuchi K, Aoki M et al (2010) Sequential arrival and graded secretion of Sema3F by olfactory neuron axons specify map topography at the bulb. Cell 141:1056-1067. https://doi. org/10.1016/j.cell.2010.04.041

Tang Y, Benusiglio D, Lefevre A et al (2020) Social touch promotes interfemale communication via activation of parvocellular oxytocin neurons. Nat Neurosci 1-13. https://doi.org/10.1038/ s41593-020-0674-y

Teng BL, Nikolova VD, Riddick NV et al (2016) Reversal of social deficits by subchronic oxytocin in two autism mouse models. Neuropharmacol 105:61-71. https://doi.org/10.1016/j. neuropharm.2015.12.025

Thye MD, Bednarz HM, Herringshaw AJ et al (2018) The impact of atypical sensory processing on social impairments in autism spectrum disorder. Dev Cogn Neurosci 29:151-167. https://doi. org/10.1016/j.den.2017.04.010

Tirko NN, Eyring KW, Carcea I et al (2018) Oxytocin transforms firing mode of CA2 hippocampal neurons. Neuron 100:593-608.e3. https://doi.org/10.1016/j.neuron.2018.09.008

Tonacci A, Billeci L, Tartarisco G et al (2017) Olfaction in autism spectrum disorders: a systematic review. Child Neuropsychol 23:1-25. https://doi.org/10.1080/09297049.2015.1081678

Tordoff MG, Ellis HT (2013) Taste dysfunction in BTBR mice due to a mutation of Itpr3, the inositol triphosphate receptor 3 gene. Physiol Genomics 45:834-855. https://doi.org/10.1152/ physiolgenomics.00092.2013

Tu Z, Zhao H, Li B et al (2019) CRISPR/Cas9-mediated disruption of SHANK3 in monkey leads to drug-treatable autism-like symptoms. Hum Mol Genet 28:561-571. https://doi.org/10.1093/ hmg/ddy 367

Uddin LQ, Menon V (2009) The anterior insula in autism: underconnected and under-examined. Neurosci Biobehav Rev 33:11981203. https://doi.org/10.1016/j.neubiorev.2009.06.002

Walum H, Young LJ (2018) The neural mechanisms and circuitry of the pair bond. Nat Rev Neurosci 19:643-654. https://doi. org/10.1038/s41583-018-0072-6

Wang CY, Liu Z, Ng YH, Südhof TC (2020) A synaptic circuit required for acquisition but not recall of social transmission of food preference. Neuron 107:144-157.e4. https://doi. org/10.1016/j.neuron.2020.04.004

Wesson DW (2013) Sniffing behavior communicates social hierarchy. Curr Biol 23:575-580. https://doi.org/10.1016/j.cub.2013.02.012

Williams KE, Gibbons BG, Schreck KA (2005) Comparing selective eaters with and without developmental disabilities. J Dev Phys Disabil 17:299-309

Wilson DA, Kadohisa M, Fletcher ML (2006) Cortical contributions to olfaction: plasticity and perception. Semin Cell Dev Biol 17:462470. https://doi.org/10.1016/j.semcdb.2006.04.008

Won H, Lee HR, Gee HY et al (2012) Autistic-like social behaviour in Shank2 -mutant mice improved by restoring NMDA receptor function. Nature 486:261-265. https://doi.org/10.1038/nature11208

Wu S, Jia M, Ruan Y et al (2005) Positive association of the oxytocin receptor gene (OXTR) with autism in the Chinese Han population. Biol Psychiat 58:74-77. https://doi.org/10.1016/j. biopsych.2005.03.013

Wu Y, Ma L, Duyck K et al (2018) A population of navigator neurons is essential for olfactory map formation during the critical period. Neuron 100:1066-1082.e6. https://doi.org/10.1016/j. neuron.2018.09.051

Xu F, Schaefer M, Kida I et al (2005) Simultaneous activation of mouse main and accessory olfactory bulbs by odors or pheromones. J Comp Neurol 489:491-500. https://doi.org/10.1002/cne.20652

Xu G, Strathearn L, Liu B, Bao W (2018) Prevalence of autism spectrum disorder among US Children and adolescents, 2014-2016. JAMA 319:81-82. https://doi.org/10.1001/ jama.2017.17812

Yizhar O, Fenno LE, Prigge M et al (2011) Neocortical excitation/ inhibition balance in information processing and social dysfunction. Nature 477:171-178. https://doi.org/10.1038/ nature 10360

Young LJ, Barrett CE (2015) Can oxytocin treat autism? Science 347:825-826. https://doi.org/10.1126/science.aaa8120

Yu GZ, Kaba H, Okutani F et al (1996) The action of oxytocin originating in the hypothalamic paraventricular nucleus on mitral and granule cells in the rat main olfactory bulb. Neuroscience 72:1073-1082. https://doi.org/10.1016/0306-4522(95)00599-4

Zerbi V, Ielacqua GD, Markicevic M et al (2018) Dysfunctional autism risk genes cause circuit-specific connectivity deficits with distinct developmental trajectories. Cereb Cortex 28:2495-2506. https://doi.org/10.1093/cercor/bhy046

Zhang HF, Dai YC, Wu J et al (2016) Plasma oxytocin and argininevasopressin levels in children with autism spectrum disorder in china: associations with symptoms. Neurosci Bull 32:423-432. https://doi.org/10.1007/s12264-016-0046-5

Zhou G, Lane G, Cooper SL et al (2019) Characterizing functional pathways of the human olfactory system. eLife 8:e47177. https:// doi.org/10.7554/eLife.47177

Publisher's Note Springer Nature remains neutral with regard to jurisdictional claims in published maps and institutional affiliations. 